\title{
Medication Adherence in a Community Population with Uncontrolled Asthma
}

\author{
Sarah Serhal ${ }^{1, *}$, Bandana Saini ${ }^{1,2}$, Sinthia Bosnic-Anticevich ${ }^{1,3}$, Ines Krass ${ }^{2}$, Frances Wilson ${ }^{1}$ \\ and Carol Armour ${ }^{1}$ \\ 1 Woolcock Institute of Medical Research, 431 Glebe Point Road, Glebe, NSW 2031, Australia; \\ bandana.saini@sydney.edu.au (B.S.); sinthia.bosnic-anticevich@sydney.edu.au (S.B.-A.); \\ f.wilson@sydney.edu.au (F.W.); carol.armour@sydney.edu.au (C.A.) \\ 2 School of Pharmacy, The University of Sydney, A15, Science Rd, Camperdown, NSW 2006, Australia; \\ ines.krass@sydney.edu.au \\ 3 School of Medical Sciences, Faculty of Medicine and Health, University of Sydney, \\ Camperdown, NSW 2006, Australia \\ * Correspondence: sarah.serhal@sydney.edu.au; Tel.: +61-4-1495-9883
}

Received: 29 July 2020; Accepted: 3 October 2020; Published: 7 October 2020

\begin{abstract}
It is well documented that the use of medications in asthma and allergic rhinitis is often suboptimal, and consequently, patients remain symptomatic. This study aimed to determine the extent and type of medication-related issues contributing to poor asthma control by profiling medication management in those most at risk-a population with clinically uncontrolled asthma. Participants $(n=363)$ were recruited from Australian community pharmacies, and a dispensed medication history report for the previous 12 months was collected to examine medication adherence and factors affecting adherence. Information was also collected regarding participant asthma control and asthma/allergic rhinitis (if applicable) management. The participants' mean asthma control score was 2.49 ( $\pm 0.89 \mathrm{SD}, \mathrm{IQR}=1.20$ ) (score $\geq 1.5$ indicative of poorly controlled asthma), and $72 \%$ were either non-adherent or yet to initiate preventer therapy. Almost half had been prescribed high doses of inhaled corticosteroid and $24 \%$ reported use of oral corticosteroids. Only $22 \%$ of participants with concomitant allergic rhinitis were using first line treatment. A logistic regression model highlighted that participant health care concession status and hospital admissions were associated with better adherence. Suboptimal medication management is evident in this at-risk population.
\end{abstract}

Keywords: asthma; allergic rhinitis; medication management; pharmacy; primary care; adherence

\section{Introduction}

Despite the availability of effective medications, asthma is responsible for 1000 deaths each day globally, and is amongst the top 20 causes of years of life lived with disability [1]. Optimal therapeutic management of asthma is needed to achieve better health-related quality of life, reduce patient and societal burden, and significantly improve patient clinical outcomes.

Asthma often occurs with a range of comorbid conditions, of which allergic rhinitis is the most common, given the shared inflammatory pathophysiology and physio-anatomic continuity between the upper and lower respiratory tracts [2-12]. Epidemiological data indicate that about $80 \%$ of people with asthma have allergic rhinitis [13]. Poor allergic rhinitis control is therefore a significant risk factor for poor asthma control $[2,3,7,8]$.

With the right medication, at the right dose, used with the correct technique, asthma and allergic rhinitis can be well controlled, and to achieve long-term control ongoing medication use is often required. However, the quality use of asthma and allergic rhinitis medications may be compromised 
at various levels of the patient care chain, and has been reported internationally [14-18]. Poor levels of adherence have been observed globally, reasons for which have been the focus of much research. A plethora of medication, patient and external factors drive both unintentional and intentional poor adherence [18-26]. Drivers often vary internationally, dependent on the sociopolitical context in which they are explored [20].

International standards for asthma management are prescribed by the Global Initiative for Asthma (GINA), and interpreted locally in Australia by the National Asthma Council Australia (NAC) $[13,23]$. It is recommended that all adults with asthma be treated with a preventer (inhaled corticosteroids (ICS)) to control symptoms, and to reduce the risk of future exacerbations and decline in lung function by reducing airway inflammation [13,23]. Reliever medications (short-acting beta 2 agonists (SABA)) are used by patients on an as-needed basis to relieve worsening symptoms or exacerbations [13]. Recently, GINA Guidelines have recommended the use of corticosteroid-containing inhalers for acute symptoms. The current guidelines recommend matching treatment to asthma control and risk of exacerbations in a stepped approach with frequent patient review, to ensure minimum long-term exposure to high-dose preventers [13]. Prescribers can scale down or step up therapy based on patient responses [13]. Most adults with asthma should be controlled on regular low-dose ICS preventer (Step 2) [13]. The goal and ultimate measure of success of asthma management is to eliminate the frequent need for emergency use of reliever medications and oral corticosteroids [13,23].

In Australian primary care, prescribing patterns that are not guideline concordant have been observed, for example the level of combination preventer (ICS and long-acting beta2-agonist (LABA)) prescribing is much higher than expected based on asthma control reported by patients [27]. Even when prescribed optimal levels of therapy, many adults with asthma do not adhere to the daily use of preventers, relying instead on relievers [14,16]. Data from the Australian Centre for Asthma Monitoring [27] showed that a third of the patients prescribed preventer inhalers (ICS) had it dispensed only once in 12 months, which differs from the guideline-based objective of adults being on regular low-dose inhaled corticosteroid to limit airway remodeling and maintaining control [27]. Even when taking preventers (ICS), many patients cannot correctly use inhalers as recommended, leading to sub-optimal dosing and unnecessary side effects [28-31]. Further, the rising costs of therapeutic management have been shown to play a role in patient decision-making regarding adherence to treatment [21,32]. Both direct and indirect expenses associated with the purchase of prescription preventer medications (ICS) for asthma can deter patient adherence and lead to a preference for relying on the less expensive reliever medications that can be purchased without a prescription in Australian pharmacies [21].

Topical anti-inflammatory and oral antihistamines for allergic rhinitis treatment can also be purchased directly from Australian pharmacies, and consequently people with allergic rhinitis often self-select medications in the pharmacy without consulting a health care professional [17], and make their decisions either experimentally or based on their own experience [33]. A recent Australian survey indicated that only $15 \%$ of surveyed allergic rhinitis patients presenting at pharmacies left with an appropriate medication [17]; most with oral antihistamines and few with the more appropriate intranasal corticosteroids. Whilst oral antihistamines may be a short-term preference in patients with asthma, given that they are cheaper and easier to use, in the long term, this may translate to poorly controlled asthma, necessitating frequent use of preventer asthma medications at higher doses. This consequence is a result of post nasal drip and upper airway irritation, which augment lower airway symptoms $[34,35]$. Therefore, the treatment of allergic rhinitis is vital for the effective management of asthma, and intranasal corticosteroids are the first-line treatment for people with allergic rhinitis and coexisting asthma [36].

Suboptimal therapeutic management of asthma and allergic rhinitis has previously been studied separately. This study aimed to determine the extent and type of medication-related issues contributing to poor asthma and allergic rhinitis control by profiling medication management in a single population most at risk-a population with clinically uncontrolled asthma. 


\section{Materials and Methods}

The study involved a cross-sectional observational study of patients presenting at their local community pharmacy between August 2018 and February 2019. All participants provided informed consent prior to enrolling in the study.

This research was part of an implementation trial approved by the Human Research Ethics Committees of The University of Sydney, Curtin University and The University of Tasmania, and funded by the Australian Government Department of Health via the 6th Community Pharmacy Agreement [37]. The implementation trial was a two-arm clustered randomized controlled trial that aimed to assess the impact of a specialized pharmacy-based intervention on asthma control compared to standard (control) care [37]. This paper analyzed baseline medication-use data collected from recruited participants with asthma in the above trial.

\subsection{Pharmacy Recruitment}

Pharmacists from regional and metropolitan areas in New South Wales, Western Australia, and Tasmania, were invited to self-nominate their interest in participating in the study via an online expression of interest form sent out by the Pharmacy Guild of Australia. Pharmacies were stratified by geographical distribution to be representative of the general population, and selected to participate using random number generation. Geographic remoteness was determined as per the Pharmacy Accessibility Remoteness Index of Australia (PhARIA)—(high accessible (PhARIA 1), accessible/moderately accessible, remote and very remote (PhARIA 2-6)) [38].

\subsection{Participant Recruitment}

Pharmacies were asked to recruit a minimum of 7 asthma participants each. The classification of asthma was based on patient self-report. The sample size was based on feasibility established in previous studies to account for predicted pharmacy and participant dropout rates and the numbers required to show significant change in the larger implementation trial $[37,39,40]$.

\subsubsection{Participant Inclusion Criteria}

The primary inclusion criteria for participants included uncontrolled asthma as determined by a score $\geq 1.5$ in the Asthma Control Questionnaire (ACQ) [41,42]. Patients aged $\geq 18$ years, who (1) were able to communicate with the pharmacist in English, (2) were a regular patient of the pharmacy (receiving medications from that pharmacy for the previous 12 months and having a dispensing history available) and (3) managed their own medications, i.e., patients were not dependent on carers (as determined by the pharmacist), were included if they consented to participate.

\subsubsection{Participant Exclusion Criteria}

Participants were excluded from the study if they (1) had a high dependence on medical care (more than 5 morbidities and specialist care), (2) were unable to manage their own medications (as determined by the pharmacist) (3) had a confirmed diagnosis of chronic obstructive pulmonary disorder (COPD) (self-reported by the participant) or (4) had a terminal illness.

\subsection{Data Collection}

Participants took part in a face-to-face comprehensive assessment of current asthma management. A web-based clinical decision support program linked to pharmacy dispensing software guided all data collection and intervention delivery. All participant responses were de-identified prior to the research team receiving the data.

\subsubsection{Asthma Control}

Asthma symptom control was assessed via the ACQ [41]. 


\subsubsection{Asthma History}

Self-reported age of asthma symptom onset, smoking status and whether a participant had received a lung function test in the last 12 months were the data collected, along with demographic information including age, gender-identity and location of residence (urbanity/rurality range).

\subsubsection{Health Care Utilization}

The self-reported number of hospitalizations and accident and emergency visits in the last 12 months was recorded.

\subsubsection{Medication History and Adherence}

Asthma medication profiles were generated for each participant using dispensed medication history data for the previous 12 months, automatically extracted from the pharmacy dispensing software. These dispensed medication reports were used to determine participant adherence to asthma medications over the 12-month period by calculating the Proportion of Days Covered (PDC), which refers to the proportion of days covered by medication dispensed (Equation (1)) [43-45].

$$
P D C=\left(\frac{\text { Number of days in the period "covered" }}{\text { Number of days in period }}\right) \times 100 \%
$$

Equation (1) Proportion of Days Covered formula. Number of Days in the period "covered" refers to the number of days the participant was covered by at least one asthma preventer medication based on the dates a prescription was dispensed, the number of devices per script, the actuations per device and the participant's prescribed dose. Number of days in period refers to the number of days between the dates of first supply of an asthma preventer medication and the date of data collection.

The PDC was only calculated for participants who had a minimum of three preventers dispensed on separate occasions in the preceding 12-month period. For the purpose of analysis, adherence was dichotomized to a PDC of $80 \%$ or greater (adherent) or a PDC of less than $80 \%$ (non-adherent) [46]. In case no instructions for medication administration appeared in the medication record or in cases where dose variability occurred, standard dosage was used to calculate the number of days covered for each medication dispensed.

Differences in characteristics between participants classified as adherent or non-adherent were explored. Further, information on asthma-related drug classes, individual medications and inhaler device type being used by participants was collated and used to compare against guideline recommendations and to determine if medication and formulations affect adherence.

\subsubsection{Current Medication Management}

Based on dispensed medication history data for the previous 12 months, medications were classified as current if they were dispensed within the 3 months prior to data collection. Using these data, we explored the current medication management of participants.

\subsubsection{Allergic Rhinitis}

All participants were asked if they had a diagnosis or were experiencing symptoms of allergic rhinitis. A proportion of participants (in accordance with the larger implementation trial [37]) were asked if they were treating their allergic rhinitis symptoms, and if so, to specify medications being used.

\subsection{Data Analysis}

Cross-sectional data collected by the project specific software were exported as an Excel spreadsheet and then imported into SPSS Version 25, where descriptive statistics were applied. 
To explore predictors of adherence, categorical variables were compared using Pearson's Chi Square test, and continuous variables were explored using a Mann-Whitney $U$ test. A significance level of $p<0.05$ was used for all statistical procedures.

A forward logistic regression was performed using variables shown to be significantly associated with adherence following initial exploratory analysis. To test the goodness of fit of the model, the Hosmer and Lemeshow test was used.

\section{Results}

\subsection{Participant Characteristics}

A total of 363 eligible participants was recruited into the study by 95 community pharmacies. Participant characteristics are detailed in Table 1.

Table 1. Profile of participants $(n=363)$.

\begin{tabular}{|c|c|c|}
\hline Factor & Values & Total $n(\%)$ \\
\hline \multirow{3}{*}{ Pharmacy State } & New South Wales & $257(70.8)$ \\
\hline & Western Australia & $64(17.6)$ \\
\hline & Tasmania & $42(11.6)$ \\
\hline \multirow{2}{*}{ Pharmacy Remoteness } & High Accessible & $241(66.4)$ \\
\hline & Accessible/Moderately accessible, remote, and very remote & $122(33.6)$ \\
\hline \multirow{2}{*}{ Age } & $>55$ years of age & $195(53.7)$ \\
\hline & $\leq 55$ years of age & $168(46.3)$ \\
\hline \multirow{3}{*}{ Sex } & Females & $252(69.4)$ \\
\hline & Males & $111(30.6)$ \\
\hline & Yes & $153(42.1)$ \\
\hline \multirow[t]{2}{*}{ Health Care Concession Status } & No & $163(44.9)$ \\
\hline & Unspecified & $47(12.9)$ \\
\hline \multirow{2}{*}{ Age of asthma onset } & $\geq 16$ years of age & $201(55.4)$ \\
\hline & $<16$ years of age & $162(44.6)$ \\
\hline \multirow{3}{*}{ Lung Function Test } & Never & $103(28.4)$ \\
\hline & Greater than 12 months ago & $164(45.2)$ \\
\hline & Within last 12 months & $96(26.4)$ \\
\hline Presentation to hospital in the past & No & $275(75.8)$ \\
\hline 12 months related to asthma & Yes & $88(24.2)$ \\
\hline \multirow{2}{*}{$\begin{array}{l}\text { At least } 1 \text { hospitalization in the } \\
\text { past } 12 \text { months related to asthma }\end{array}$} & No & $307(84.6)$ \\
\hline & Yes & $56(15.4)$ \\
\hline \multirow{2}{*}{ Active Smoker } & No & $311(85.7)$ \\
\hline & Yes & $52(14.3)$ \\
\hline \multirow{2}{*}{ History of allergic rhinitis } & Yes & $259(71.3)$ \\
\hline & No & $104(28.7)$ \\
\hline \multirow{3}{*}{ ACQ Score } & Mean & $2.49( \pm 0.89 \mathrm{SD})$ \\
\hline & Median & 2.20 \\
\hline & Q1; Q3 (IQR) & $1.80 ; 3.00(1.20)$ \\
\hline
\end{tabular}

\subsection{Asthma Control}

Participants reported a mean ACQ score of 2.49 ( \pm 0.89 SD), scores ranged from 1.50 to 5.67.

\subsection{Asthma Medication Management Over Preceding 12 Months}

Of the 363 participants, only $80 \%$ had at least one asthma ICS preventer dispensed in the preceding 12 months, with combined ICS + LABA (76\%) being the most dispensed drug class (Table 2). Seretide (fluticasone propionate/salmeterol xinafoate) pMDI $250 \mathrm{mcg} / 25 \mathrm{mcg}$ was the most dispensed preventer medication. A full list of the respiratory medications dispensed in the preceding 12 months by formulation, trade name and strength is presented in Appendix A. 
Table 2. Medications dispensed over the previous 12 months by drug class ( $n=363$ participants).

\begin{tabular}{|c|c|}
\hline Medication Type & Frequency $n(\%)$ \\
\hline Respiratory medications dispensed (incl. relievers and preventers) & $322(88.7)$ \\
\hline Any preventer medication dispensed $\left(\mathrm{ICS}^{1}\right.$ with or without $\mathrm{LABA}^{2}$, or $\mathrm{LTRA}^{3}$ ) & $292(80.4)$ \\
\hline SABA Reliever ${ }^{4}$ & $203(55.9)$ \\
\hline Oral corticosteroid dispensed (Prednisone/Prednisolone 25 mg) & $88(24.2)$ \\
\hline ICS + LABA & $275(75.8)$ \\
\hline ICS & $27(7.4)$ \\
\hline LTRA & $6(1.7)$ \\
\hline Theophylline & $5(1.4)$ \\
\hline LABA & $4(1.1)$ \\
\hline Cromones (Mast Cell stabilizers) & $3(0.8)$ \\
\hline Monoclonal Antibody & $1(0.3)$ \\
\hline Nebules & $34(9.4)$ \\
\hline Salbutamol & $30(8.3)$ \\
\hline Ipratropium & $14(3.9)$ \\
\hline Add-on therapy ${ }^{5}$ & $88(24.2)$ \\
\hline LAMA & $68(18.7)$ \\
\hline SAMA & $20(5.5)$ \\
\hline LAMA + LABA & $11(3.0)$ \\
\hline $\mathrm{LABA}+\mathrm{LAMA}+\mathrm{ICS}$ & $8(2.2)$ \\
\hline
\end{tabular}

Note: ${ }^{1}$ ICS $=$ inhaled corticosteroid; ${ }^{2}$ LABA $=$ long-acting beta2-agonist; ${ }^{3}$ LTRA $=$ leukotriene receptor antagonist; ${ }^{4} \mathrm{SABA}=$ short-acting beta2-agonist, $\mathrm{SABA}$ recorded does not include that used via nebule; ${ }^{5}$ Add-on therapy includes LAMA = long-acting muscarinic antagonist, SAMA = short-acting muscarinic antagonists and LAMA + LABA, LABA + LAMA + ICS combinations.

Over the 12-month period, the total number of different asthma preventer medications taken by participants ranged between 1 and 3 , medicines with a mean of $1.2( \pm 0.6)$.

Pressurized metered dose inhalers (pMDI) were the most common device type dispensed over the 12-month period (43\%) (Table 3), with $74 \%$ of participants collecting at least one pMDI device, whether for preventative or reliever therapy. Add-on therapy was dispensed for $24 \%$ of the population, with the most common drug class being a long-acting muscarinic antagonist (LAMA). Almost one-quarter (24\%) of participants had oral corticosteroids dispensed in the previous 12 months.

Table 3. Medications dispensed by formulation as available in Australia-excluding short-acting reliever medications ( $n=302$ participants).

\begin{tabular}{ll}
\hline \multicolumn{1}{c}{ Device Type } & \multicolumn{1}{c}{ Frequency $\boldsymbol{n} \mathbf{( \% )}$} \\
\hline Pressurized Metered Dose Inhaler (pMDI) & $132(43.7)$ \\
Turbuhaler & $75(24.8)$ \\
Accuhaler & $73(24.2)$ \\
Ellipta & $52(17.2)$ \\
Respimat & $33(10.9)$ \\
Handihaler & $30(9.9)$ \\
Rapihaler & $26(8.6)$ \\
Spiromax & $15(5.0)$ \\
Oral tablet & $10(3.3)$ \\
Breezehaler & $7(2.3)$ \\
Genuair & $4(1.3)$ \\
Autohaler & $1(0.3)$ \\
Syringe & $1(0.3)$ \\
Syrup & $1(0.3)$ \\
\hline
\end{tabular}




\subsection{Adherence to Preventer Therapy}

Participants collected an asthma preventative medication, on average, five $( \pm 5.1 \mathrm{SD})$ times over the 12-month time period. This ranged from 0 to 32 times over 12 months, as presented in Figure 1.

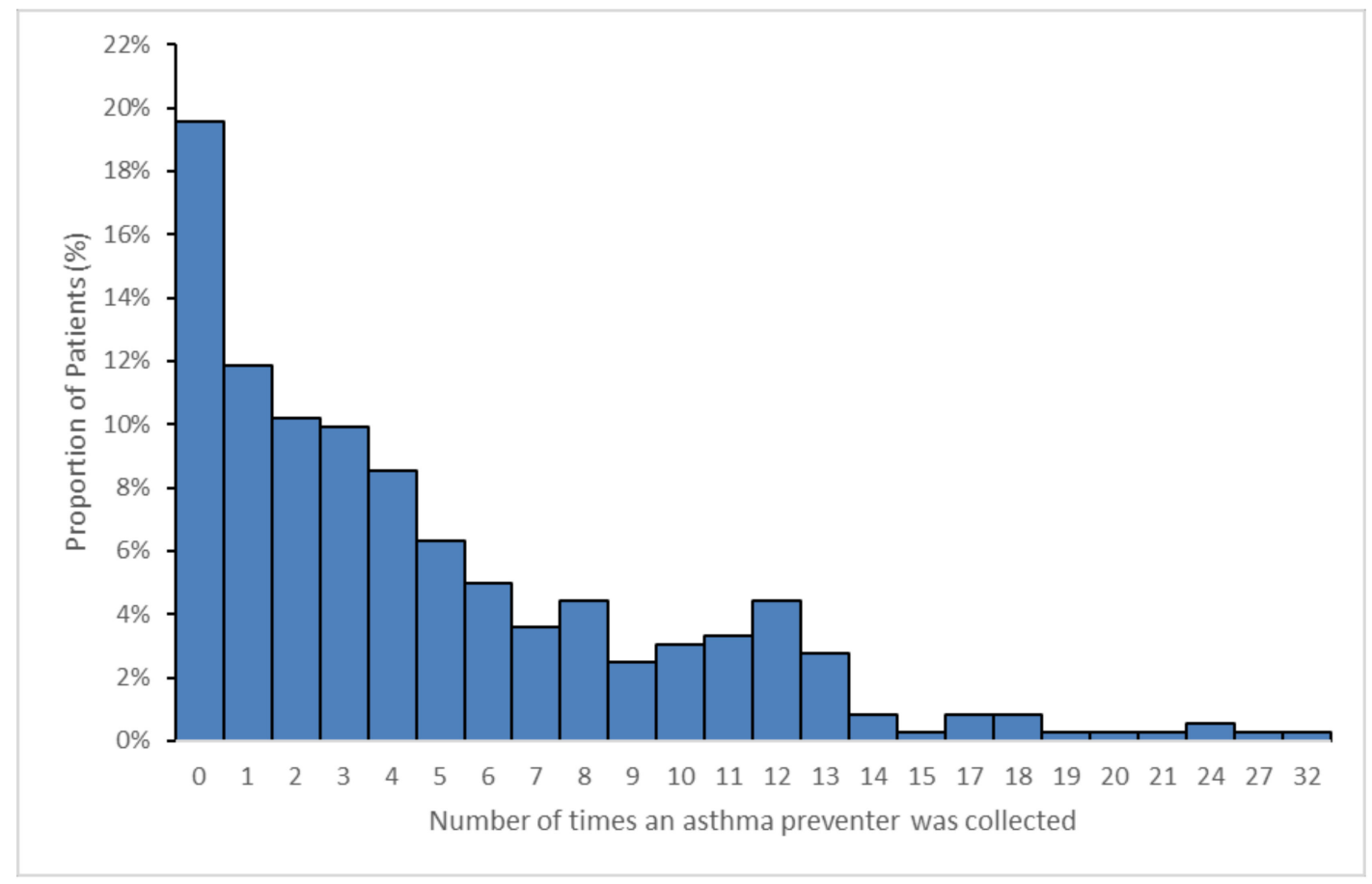

Figure 1. Number of times an asthma preventer medication was collected by participants over a 12-month period $(n=363)$.

Of the 363 participants, $42 \%(n=151)$ had preventative medication dispensed less than three times, and therefore a valid PDC score could not be calculated. These participants were deemed non-adherent for the purposes of this study.

For the remaining 212 participants, the PDC was calculated. Only $49 \%(n=103)$ of these participants were reported as adherent (PDC $\geq 80 \%)$.

Thus, out of all the participants $(n=363)$, only $28 \%(n=103)$ were considered adherent to their preventative therapy, with $52 \%(n=189)$ non-adherent to preventer therapy and $20 \%(n=71)$ having no preventer dispensed at all in the preceding 12 months.

\subsection{Factors Associated with Adherence}

Univariate analysis showed statistically significant positive associations between the number of hospital presentations $(p=0.009)$, older participant age $(p=0.026)$, confirmed health care concession status $(p=0.001)$, sole use of an Ellipta device $(p=0.042)$, use of a LABA only medication $(p=0.038)$, and use of a LAMA + LABA combination medication $(p=0.046)$ with a participant being adherent. There was a negative association between sole use of a Turbuhaler $(0.004)$ and adherence.

There were no significant relationships between adherence and participant location (state or remoteness), gender, age of asthma onset, lung function status, smoking status, presence of comorbid allergic rhinitis, hospital admissions, exacerbations (indicated by oral corticosteroid in participant medication history), other device types or medication class, number of different asthma preventer medications and devices used over the previous 12 months, or medication dosage or device type variability that occurred in the previous 12 months. These variables were not included in the final model.

A forward logistic regression consistently selected or retained greater than one hospital presentation $(\mathrm{OR}=8.386(95 \%$ CI: $2.049,34.326))$ and health care concession status (OR $=0.365(95 \%$ CI: $0.196,0.680))$ 
as variables associated with better adherence, and sole use of a Turbuhaler preventer $(\mathrm{OR}=3.077$ (95\% CI: 1.322, 7.160)) was associated with poor adherence. This model fitted the data well (Hosmer and Lemeshow test $\chi^{2}=2.92, \mathrm{df}=4, p=0.570$ ).

\subsection{Current Medication Management}

In the 3 months prior to data collection, as an indicator of current asthma management, preventer therapy was present in the records of $86 \%(n=240)$ of these participants. ICS/LABA combination was the most used drug classes $(80 \%)$. Nearly half $(45 \% n=108)$ of these participants had been dispensed high-dose ICS or ICS + LABA. Very few were on low-dose ICS (Table 4).

Table 4. Inhaled corticosteroid doses currently taken by participants ( $n=240$ participants).

\begin{tabular}{lll}
\hline \multicolumn{1}{c}{ Medication Class } & \multicolumn{1}{c}{ ICS Strength } & \multicolumn{1}{c}{ Frequency $\boldsymbol{n} \mathbf{( \% )}$} \\
\hline ICS $^{1}+$ LABA $^{2}$ & & $225(93.8)$ \\
& Low $^{3}$ & $20(8.9)$ \\
& Medium $^{4}$ & $103(45.8)$ \\
& High $^{5}$ & $102(45.3)$ \\
& & $23(9.6)$ \\
ICS $^{1}$ & Low $^{3}$ & $3(13.0)$ \\
& Medium & $12(52.2)$ \\
& High $^{5}$ & $8(34.8)$ \\
\hline
\end{tabular}

Note: ${ }^{1}$ ICS $=$ inhaled corticosteroid; ${ }^{2}$ LABA = long-acting beta2-agonist; ${ }^{3}$ Low ICS = Beclometasone Dipropionate (100-200 mcg), Budesonide (200-400 mcg), Ciclesonide $(80-160 \mathrm{mcg})$, fluticasone propionate $(100-200 \mathrm{mcg})$; ${ }^{4}$ Medium ICS = Beclometasone Dipropionate (250-400 mcg), Budesonide (500-800 mcg), Ciclesonide (240-320 mcg), fluticasone furoate $(100 \mathrm{mcg})$, fluticasone propionate $(250-500 \mathrm{mcg}) ;{ }^{5} \mathrm{High}$ ICS = Beclometasone Dipropionate (>400 mcg), Budesonide (>800 mcg), Ciclesonide (>320 mcg), fluticasone furoate $(200 \mathrm{mcg})$, fluticasone propionate (>500 mcg).

The total number of asthma preventer medications taken currently by participants ranged from 1 to 3 medicines, with a mean of $0.67( \pm 0.60)$.

The combinations of respiratory medications taken by these participants are presented in Appendix B. Of these participants, 9\% were using SABA alone to manage their asthma. The most prevalent combination of therapy was ICS + LABA and a SABA, used by $31 \%$ of participants. Add-on therapy was used by $25 \%$ of participants.

\subsection{Allergic Rhinitis}

Allergic rhinitis was reported by $71 \%(n=259)$ of participants.

Allergic Rhinitis Management

A subset of participants $(n=152)$ who reported symptoms of allergic rhinitis were asked if they were treating their allergic rhinitis, the results of which are depicted in Table 5. Of these participants, $49 \%$ were using medications to help manage allergic rhinitis symptoms. Sole therapy with an oral antihistamine was the most common management strategy (20\%). Where a participant was taking more than one medication, the most common combination was oral antihistamine and intranasal corticosteroid (9\%). Only $22 \%$ of the total 152 participants with poorly controlled asthma who were asked about their allergic rhinitis management used an intranasal corticosteroid. 
Table 5. Medications used by those treating allergic rhinitis symptoms ( $n=152$ participants).

\begin{tabular}{ll}
\hline Participants Treating Allergic Rhinitis Symptoms & Frequency $\boldsymbol{n}(\mathbf{\%})$ \\
\hline Yes & $77(49.3)$ \\
No & $75(50.7)$ \\
Medication Combinations Used & $31(20.4)$ \\
Oral antihistamine & $14(9.2)$ \\
Oral antihistamine + intranasal corticosteroid & $9(5.9)$ \\
Intranasal corticosteroid & $4(2.6)$ \\
Oral antihistamine + intranasal corticosteroid + intranasal saline & $4(2.6)$ \\
Oral antihistamine + intranasal decongestant & $3(2.0)$ \\
Oral antihistamine + oral decongestant & $2(1.3)$ \\
Oral antihistamine + intranasal corticosteroid + ocular antihistamine & $2(1.3)$ \\
Oral antihistamine + intranasal saline & $1(0.7)$ \\
Oral antihistamine + intranasal antihistamine & $1(0.7)$ \\
Oral antihistamine + ocular antihistamine & $1(0.7)$ \\
Oral antihistamine + ocular antihistamine + oral decongestant & $1(0.7)$ \\
Oral antihistamine + intranasal corticosteroid + intranasal saline + ocular saline & $1(0.7)$ \\
Oral antihistamine + intranasal decongestant + intranasal corticosteroid + intranasal saline \\
Intranasal corticosteroid + intranasal saline & $1(0.7)$ \\
Intranasal corticosteroid + oral decongestant & $1(0.7)$ \\
Ocular antihistamine & $1(0.7)$ \\
\hline
\end{tabular}

\section{Discussion}

Our study was able to profile asthma and allergic rhinitis within a single at-risk population. Based on the findings, a significant gap remains between evidence-based guidelines and current medication management in people with asthma. It is known that the appropriate use of medications can significantly improve therapeutic outcomes for people with asthma; thus, monitoring pharmacy medication dispensing records provides a mechanism for recognizing the under-use of medications and identifying the concordance of asthma management with evidence-based guidelines [27]. By profiling medication management in those most at risk-a population with clinically uncontrolled asthma-this study found that medication adherence and suboptimal treatment were significant issues.

All the participants in our study had poorly controlled asthma as assessed by the asthma control questionnaire (ACQ) [41]. This is a recognized method for assessing the risk of future exacerbations and identifying symptom severity $[41,42,47,48]$. Guidelines state that most people with asthma should be well controlled on a low-dose ICS alone-Step 2 therapy [13]. In the previous 12 months, $42 \%$ of our participants $(n=151)$ had preventer medication dispensed fewer than 3 times, whereas for optimal control they should have had 11-12 prescriptions dispensed. When we explored the proportion of days covered by preventer medication, under half of those for which a value could be calculated were adherent. Thus, it is not surprising that their asthma was not controlled.

A previous cross-sectional study which surveyed adults with asthma $(n=2686)$ in an Australian context found that $57 \%$ of the population that reported uncontrolled asthma symptoms were non-adherent or were not using a preventer. Our study found that $72 \%$ of participants with uncontrolled asthma symptoms appeared to be non-adherent or were not using a preventer. This indicates that suboptimal adherence amongst poorly controlled asthma participants is a larger problem than earlier estimates suggest, and remains unresolved.

When reviewing the strength of ICS being used by study participants, $93 \%$ had been prescribed medium (48\%) to high (45\%) ICS doses. Very few were on low-dose ICS. These data support previous evidence that higher doses of ICS may be overprescribed in Australia [49]. Additionally, one in four participants had used oral corticosteroids in the previous 12 months-indicating a lack of asthma control. These data suggest that there may be problems regarding the prescribing of asthma medications, and that undetected suboptimal adherence may be interpreted as poor therapeutic response, perpetuating a cycle of uncontrolled asthma symptoms, review and therapy escalation. The results may also suggest the presence of severe or difficult-to-treat asthma [23]. The high prevalence 
of poor adherence to preventer therapy or a lack of preventer therapy is consistent with international studies, despite variations in thresholds and measurements used to classify adherence [50]. For example, a study conducted in the United States of America (USA), using the PDC method and a cut off of $80 \%$ or greater for adherence, found that only $20 \%$ of fluticasone propionate users (an ICS) were adherent to therapy over a one-year period [50,51]. A European study exploring asthma control and management in 8000 patients found only $48 \%$ self-reported using their preventer everyday [52]. A study from the United Kingdom found that up to $76 \%$ of patients with asthma used fewer than 10 ICS canisters in a year, which was based on the number of cannisters prescribed [50,53]. There is a clear need for standardized measures of adherence for respiratory measurement to allow for global comparisons in asthma maintenance.

All participants within this study cohort should be on preventer therapy. The $20 \%$ of participants who were not on preventive therapy represent people with asthma who are falling between the cracks of primary care. As we can only report on what a participant had chosen to get dispensed at the pharmacy, we have no way to determine whether or not the participant has sought general practitioner care, a preventer medication has yet been prescribed, the participant has collected the medication from another pharmacy, or the participant has chosen to not have the item dispensed for any personal reasons, including cost, adverse effects, or personal beliefs and knowledge about asthma and its management. However, this is a population (those with uncontrolled asthma and poor adherence) that pharmacists can assist in identifying and initiating care pathways for by referring them to their general practitioner. Greater vigilance regarding patient preventer medication dispensing or lack thereof will assist in minimizing this proportion of at-risk patients.

There is still a proportion of the participants whose lack of control is not explained by poor adherence. Therefore, more investigation is required to determine why control has not been achieved in this population despite adherence to medications. Other possible explanations include poor inhaler technique, suboptimal prescribing of respiratory medication, discarding medications that have been collected, the presence of severe asthma requiring specialist care, or the presence of untreated or poorly managed co-morbidities that are known to affect asthma control, such as gastro-oesophageal reflux disease $[13,54]$, sleep-related issues such as sleep apnoea [55], obesity $[13,56]$, and depression or anxiety $[13,57,58]$.

One in four study participants were using add-on respiratory agents in addition to the asthma medications specified in international guidelines, including the addition of LAMA, SAMA, LAMA + LABA combinations or triple therapy. This may be indicative of advanced Step 4 therapy or Step 5 therapy-the highest level of asthma management [13,23]. It is difficult to determine if this is in fact an indication of severe asthma, the presence of Asthma-COPD Overlap Syndrome, inappropriate prescribing, a lack of fidelity to the exclusion criteria which asked pharmacists to exclude people with COPD, or the participants' understanding of their own diagnosis [59]. Studies have reported a lack of recognition by participants of COPD diagnosis, and diagnostic confusion between COPD and asthma $[60,61]$. Often, if asthma was the lifelong diagnosis, this diagnosis title can remain and patients do not see COPD as a separate diagnosis, or they may not be told they have COPD [62].

A high proportion of participants presented with comorbid allergic rhinitis (71\%), which is close to population estimates for those with asthma [13]. Suboptimal management of allergic rhinitis was apparent, as half of the cohort did not report using any treatments to address their symptoms. The optimal therapy for participants with uncontrolled asthma and allergic rhinitis is the regular use of an intranasal corticosteroid. However, just over one in five participants who were asked about their allergic rhinitis management were using an intranasal corticosteroid; this should be higher. Thus, poorly controlled allergic rhinitis may be one of the factors influencing the lack of asthma control in our community cohort, although our exploratory analysis and regression did not show this.

The univariate analysis indicated that those more likely to be adherent were participants who had had a hospitalization, were older or were patients with a health care concession, which is not surprising. A hospitalization for asthma would focus the person with asthma on the need to control 
their disease with the appropriate use of medication. This could be an opportunity for pharmacists to maintain this awareness and focus on how to keep well. Furthermore, it has been shown that younger adults have lower rates of adherence than older adults with asthma [63-67]. Despite previous studies suggesting other risks associated with poor adherence, the number of medications and the severity of the disease was not associated with better/poorer adherence in our cohort of participants. In Australia, some residents, including seniors, government social security allowance recipients and low-paid workers, are eligible for health care concessions, which allow access to prescription items and medical services at a discounted rate. For some asthma preventer medications, this could mean a saving of AUD 34.40 per supply, as per 2020 patient contribution fees [68,69]. It is known that out-of-pocket expenses can be a driving force in patient decision-making regarding adherence to therapy [21,32]. Our results supported this, showing that participants with a health care concession, who pay significantly less for preventer medications, were more adherent than those without.

Certain types of devices were found to be significantly associated with improved adherence (Ellipta device users) or with lower adherence (Turbuhaler, if this was the only device the participant was using). It could be speculated that because the Turbuhaler has a higher internal resistance than other dry powder inhalers, greater force is required to inhale the required dose. As greater effort is required, participants not using the device correctly may not have been receiving the therapeutic dose, and therefore would not have received the adequate effect. Additionally, the Turbuhaler device may also be deemed somewhat cumbersome as it requires precise positioning (upright) during activation, and inhalation has no perceivable taste or smell sensation. This may have led to the belief that the medication is not effective, or an overall dissatisfaction with the device and impact adherence. Conversely, the Ellipta is easier to use, and medications formulated in this device have only once-daily dosage requirements, which may indicate why Ellipta users were more adherent. Patient satisfaction with respiratory device type has been previously shown to positively impact adherence and improve therapeutic outcomes [70], however preferences are subjective and variable [67,70]. More research is required to examine the association between respiratory device type and patient adherence, as existing studies have produced contradictory outcomes $[67,71-73]$.

Our results indicate that the identification of people with asthma who need adherence support and education is difficult based on characteristics alone, and greater vigilance is required in monitoring medication collection for each patient.

\section{Limitations}

Preventer medications in Australia are scheduled as prescription only, and so we have a clear data trail for each of these purchases. The medication usage data presented are representative of what has been recorded for each recipient at the recruiting community pharmacy. We cannot be certain that the participant had not collected other medications elsewhere. To help mitigate this issue, inclusion criterion for the trial were included to ensure that the participant was a regular patient at the pharmacy, and the pharmacists received training to ensure this. This criterion allowed us to see dosage instructions so as to measure adherence accurately. Additionally, we can only report on what participants had chosen to get dispensed, which does not mean other medication was not prescribed and not taken to the pharmacy.

To the best of our knowledge, the application of PDC calculations has not previously been undertaken to determine adherence to asthma therapy. People with asthma are known to self-titrate their medications in response to their symptoms, and so dosage variability may exist. Thus, there may be different perspectives on what constitutes adherence from an individual perspective versus clinical calculation.

Short-acting beta 2 agonists in Australia were available without a prescription at the time the study was conducted. However, some people purchase them with a prescription if they are eligible for health benefits through a government health care concession, as a large proportion of the cost becomes 
subsidized. For this reason, the data we have on short-acting beta 2 agonists are only representative of those with a health care concession card, and are missing for the remaining cohort.

All participant co-morbidities, other respiratory illnesses or recent experiences with acute illness, and the degree to which these may have impacted medicine use and control or impacted on quality of life, are unknown. However, our inclusion criteria for participation asked pharmacists to exclude people with COPD from the trial. Our study relied on patient self-reporting a COPD diagnosis, as we cannot clinically differentiate between asthma and COPD within a pharmacy setting.

Pharmacies were sampled from areas of differing rurality, which matched the distribution of the Australian population, and thus the cohort is representative of our region. In total, 95 pharmacies recruited on average four participants each. There was no significant difference in recruitment rate between the states in Australia.

\section{Conclusions}

In Australia, it is estimated that approximately half of the people with asthma have poorly controlled asthma [16]. By exploring medication use for the population most at risk of future exacerbations, i.e., those with uncontrolled asthma, we were able to determine medication-related practices that perpetuate poor control. Poor choices at a patient or primary care level have the power to cause further individual- and community-based burdens clinically, socially and economically. Our results support previous research which has shown that adherence to preventer medication in people with asthma is poor in a large proportion of the population with asthma, particularly those who have poorly controlled asthma.

Health care system improvements are needed to target practices that compromise patient care and that increase the preventable risk associated with the suboptimal medication management of both asthma and allergic rhinitis. Pharmacists are in an excellent position to identify those with poorer adherence via their dispensing records. More work is required to pinpoint target characteristics that can more efficiently identify individuals with adherence issues, and form the inclusion criteria for future programs.

Author Contributions: Conceptualization, B.S., S.B.-A. and C.A.; Data curation, S.S. and F.W.; Formal analysis, S.S. and I.K.; Funding acquisition, C.A.; Methodology, S.S., I.K., F.W. and C.A.; Project administration, S.S. and C.A.; Supervision, B.S., S.B.-A. and C.A.; Visualization, B.S., S.B.-A., I.K. and C.A.; Writing-Original draft, S.S. and C.A.; Writing-Review and editing, S.S., B.S., S.B.-A., I.K. and C.A. All authors have read and agreed to the published version of the manuscript.

Funding: This work was supported by the Commonwealth of Australia as represented by the Department of Health via The Sixth Community Pharmacy Agreement (6CPA).

Conflicts of Interest: The authors declare no conflict of interest. The funders had no role in the design of the study, in the collection, analyses, or interpretation of data or in the writing of the manuscript.

\section{Abbreviations}

$\begin{array}{ll}\text { ACQ } & \text { Asthma Control Questionnaire } \\ \text { COPD } & \text { Chronic Obstructive Pulmonary Disease } \\ \text { GINA } & \text { Global Initiative for Asthma } \\ \text { ICS } & \text { Inhaled corticosteroid } \\ \text { LTRA } & \text { Leukotriene receptor antagonist } \\ \text { LABA } & \text { Long-acting beta2-agonist } \\ \text { LAMA } & \text { Long-acting muscarinic antagonist } \\ \text { NAC } & \text { National Asthma Council Australia } \\ \text { pMDI } & \text { Pressurized Metered Dose Inhaler } \\ \text { PDC } & \text { Proportion of Days Covered } \\ \text { SABA } & \text { Short-acting beta2-agonist } \\ \text { SAMA } & \text { Short-acting muscarinic antagonists }\end{array}$




\section{Appendix A. Medication Dispensed by Brand Name and Strength}

Asthma preventative medications dispensed in the 12 months prior to data collection by formulation, trade name and strength are presented in Table A1.

Table A1. Asthma preventers dispensed over the previous 12 months ( $n=292$ participants).

\begin{tabular}{|c|c|c|c|}
\hline Formulation & Trade Name & Strength & Frequency $n(\%)$ \\
\hline Fluticasone Propionate/Salmeterol & Seretide MDI & $250 \mathrm{mcg} / 25 \mathrm{mcg}$ & $85(29.1)$ \\
\hline Budesonide/Formoterol Fumarate Dihydrate & Symbicort Turbuhaler & $200 \mathrm{mcg} / 6 \mathrm{mcg}$ & $42(14.4)$ \\
\hline Fluticasone Propionate/Salmeterol & Seretide Accuhaler & $250 \mathrm{mcg} / 50 \mathrm{mcg}$ & $36(12.3)$ \\
\hline Fluticasone Propionate/Salmeterol & Seretide Accuhaler & $500 \mathrm{mcg} / 50 \mathrm{mcg}$ & $27(9.2)$ \\
\hline Budesonide/Formoterol Fumarate Dihydrate & Symbicort Turbuhaler & $400 \mathrm{mcg} / 12 \mathrm{mcg}$ & $27(9.2)$ \\
\hline Budesonide/Formoterol Fumarate Dihydrate & Symbicort Rapihaler & $200 \mathrm{mcg} / 6 \mathrm{mcg}$ & $24(8.2)$ \\
\hline Fluticasone Furoate/Vilanterol & Breo Ellipta & $200 \mathrm{mcg} / 25 \mathrm{mcg}$ & $18(2.2)$ \\
\hline Fluticasone Furoate/Vilanterol & Breo Ellipta & $125 \mathrm{mcg} / 25 \mathrm{mcg}$ & $15(6.2)$ \\
\hline Budesonide/Formoterol Fumarate Dihydrate & DuoResp Spiromax & $400 \mathrm{mcg} / 12 \mathrm{mcg}$ & $12(4.1)$ \\
\hline Ciclesonide & Alvesco MDI & $160 \mathrm{mcg}$ & $11(3.8)$ \\
\hline Fluticasone Propionate & Flixotide, Fluticasone Cipla MDI & $250 \mathrm{mcg}$ & $8(2.7)$ \\
\hline Fluticasone Propionate/Salmeterol & Seretide, F/S Cipla, Salplusf MDI & $125 \mathrm{mcg} / 25 \mathrm{mcg}$ & $8(2.7)$ \\
\hline Fluticasone Propionate & Flixotide, Fluticasone Cipla MDI & $125 \mathrm{mcg}$ & $7(2.4)$ \\
\hline Montelukast & Singulair, Respikast, Lukaira, Montelukast Tabs & $10 \mathrm{mg}$ & $6(2.1)$ \\
\hline Fluticasone Propionate & Flixotide Accuhaler & $250 \mathrm{mcg}$ & $5(1.7)$ \\
\hline Fluticasone Propionate/Formoterol Fumarate Dihydrate & Flutiform MDI & $250 \mathrm{mcg} / 10 \mathrm{mcg}$ & $5(1.7)$ \\
\hline Fluticasone Propionate/Formoterol Fumarate Dihydrate & Flutiform MDI & $125 \mathrm{mcg} / 5 \mathrm{mcg}$ & $4(1.4)$ \\
\hline Theophylline & Nuelin SR & $250 \mathrm{mg}$ & $4(1.4)$ \\
\hline Budesonide & Pulmicort Turbuhaler & $400 \mathrm{mcg}$ & $3(1.0)$ \\
\hline Budesonide/Formoterol Fumarate Dihydrate & DuoResp Spiromax & $200 \mathrm{mcg} / 6 \mathrm{mcg}$ & $3(1.0)$ \\
\hline Salmeterol & Serevent Accuhaler & $50 \mathrm{mcg}$ & $2(0.7)$ \\
\hline Fluticasone Propionate/Salmeterol & Seretide Accuhaler & $100 \mathrm{mcg} / 50 \mathrm{mcg}$ & $2(0.7)$ \\
\hline Budesonide/Formoterol Fumarate Dihydrate & Symbicort Turbuhaler & $100 \mathrm{mcg} / 6 \mathrm{mcg}$ & $2(0.7)$ \\
\hline Budesonide/Formoterol Fumarate Dihydrate & Symbicort Rapihaler & $100 \mathrm{mcg} / 3 \mathrm{mcg}$ & $2(0.7)$ \\
\hline Formoterol Fumarate Dihydrate & Oxis Turbuhaler & $6 \mathrm{mg}$ & $1(0.3)$ \\
\hline Sodium Cromoglycate & Intal MDI & $1 \mathrm{mg}$ & $1(0.3)$ \\
\hline Sodium Cromoglycate & Intal MDI & $5 \mathrm{mg}$ & $1(0.3)$ \\
\hline Nedocromil Sodium & Tilade MDI & $2 \mathrm{mg}$ & $1(0.3)$ \\
\hline Fluticasone Propionate & Flixotide Accuhaler & $500 \mathrm{mcg}$ & $1(0.3)$ \\
\hline Beclometasone Dipropionate & Qvar Autohaler & $100 \mathrm{mcg}$ & $1(0.3)$ \\
\hline Fluticasone Propionate/Salmeterol & Seretide, F/S Cipla, Salplusf MDI & $50 \mathrm{mcg} / 25 \mathrm{mcg}$ & $1(0.3)$ \\
\hline Omalizumab & Xolair Syringe & & $1(0.3)$ \\
\hline Theophylline & Nuelin Syrup & $133.3 \mathrm{mg} / 25 \mathrm{~mL}$ & $1(0.3)$ \\
\hline
\end{tabular}

\section{Appendix B. Combination Therapy}

Combinations of medications dispensed in the 3 months prior to data collection are presented in Tables A2-A4.

Table A2. Combination therapy in 3 months preceding control assessment-All respiratory medications ( $n=280$ participants).

\begin{tabular}{ll}
\hline Medication Combination & Frequency $\boldsymbol{n}(\mathbf{\%})$ \\
\hline (ICS + LABA) (SABA) & $88(31.4)$ \\
(ICS + LABA) & $77(27.5)$ \\
(SABA) & $25(8.9)$ \\
(ICS + LABA) (SABA)(LAMA) & $22(7.9)$ \\
(ICS + LABA) (LAMA) & $14(5.0)$ \\
(ICS) & $6(2.1)$ \\
(ICS + LABA) (Cromone) & $4(1.4)$ \\
(ICS) (ICS + LABA) (LAMA) & $3(1.1)$ \\
(ICS + LABA) (SABA) (SAMA) & $3(1.1)$ \\
(LAMA) & $3(1.1)$ \\
(SABA) (LAMA) & $3(1.1)$ \\
(ICS) (ICS + LABA) (SABA) & $2(0.7)$ \\
(ICS) (LABA) & $2(0.7)$ \\
(ICS) (SABA) & $2(0.7)$ \\
(ICS) (SABA) (LAMA + LABA) & $2(0.7)$ \\
(LAMA + LABA + ICS) & $2(0.7)$ \\
\hline
\end{tabular}


Table A2. Cont

\begin{tabular}{ll}
\hline Medication Combination & Frequency $\boldsymbol{n} \mathbf{( \% )}$ \\
\hline (SABA) (LAMA + LABA) & $2(0.7)$ \\
(SABA) (LAMA + LABA + ICS) & $2(0.7)$ \\
(ICS) (ICS + LABA) & $1(0.4)$ \\
(ICS) (ICS + LABA) (SABA) (LAMA) & $1(0.4)$ \\
(ICS) (ICS + LABA) (SABA) (LAMA) (LAMA + LABA) & $1(0.4)$ \\
(ICS) (LABA) (SABA) (LAMA) & $1(0.4)$ \\
(ICS) (LAMA + LABA) & $1(0.4)$ \\
(ICS) (SABA) (THEOPH) & $1(0.4)$ \\
(ICS + LABA) (LAMA) (LAMA + LABA) & $1(0.4)$ \\
(ICS + LABA) (LTRA) & $1(0.4)$ \\
(ICS + LABA) (MONOAB) & $1(0.4)$ \\
(ICS + LABA) (Cromone) (LAMA + LABA) & $1(0.4)$ \\
(ICS + LABA) (Cromone) (SABA) & $1(0.4)$ \\
(ICS + LABA) (Cromone) (SABA) (LAMA) & $1(0.4)$ \\
(ICS + LABA) (SABA) (LAMA)(LAMA + LABA + ICS) & $1(0.4)$ \\
(ICS + LABA) (SABA) (LAMA) (SAMA) & $1(0.4)$ \\
(ICS + LABA) (THEOPH) (LAMA) & $1(0.4)$ \\
(LAMA + LABA) & $1(0.4)$ \\
(LTRA) (SABA) (LAMA + LABA + ICS) & $1(0.4)$ \\
(SABA) (SAMA) (LAMA + LABA + ICS) & $1(0.4)$ \\
\hline
\end{tabular}

Table A3. Combination therapy in 3 months preceding control assessment-Asthma medications only ( $n=274$ participants).

\begin{tabular}{ll}
\hline Medication Combination & Frequency $\boldsymbol{n}(\mathbf{\%})$ \\
\hline (ICS + LABA) (SABA) & $115(42.0)$ \\
(ICS + LABA) & $92(33.6)$ \\
(SABA) & $33(12.0)$ \\
(ICS) & $7(2.6)$ \\
(ICS + LABA) (Cromone) & $5(1.8)$ \\
(ICS) (ICS + LABA) & $4(1.5)$ \\
(ICS) (ICS + LABA) (SABA) & $4(1.5)$ \\
(ICS) (SABA) & $4(1.5)$ \\
(ICS) (LABA) & $2(0.7)$ \\
(ICS + LABA) (Cromone) (SABA) & $2(0.7)$ \\
(ICS) (LABA) (SABA) & $1(0.4)$ \\
(ICS) (SABA) (THEOPH) & $1(0.4)$ \\
(ICS + LABA) (LTRA) & $1(0.4)$ \\
(ICS + LABA) (MONOAB) & $1(0.4)$ \\
(ICS + LABA) (THEOPH) & $1(0.4)$ \\
(LTRA) (SABA) & $1(0.4)$ \\
\hline
\end{tabular}

Table A4. Combination therapy in 3 months preceding control assessment-Add-on therapies ( $n=69$ participants).

\begin{tabular}{ll}
\hline Medication Combination & Frequency $\boldsymbol{n}(\mathbf{\%})$ \\
\hline (LAMA) & $49(71.0)$ \\
(LAMA + LABA) & $7(10.1)$ \\
(LAMA + LABA + ICS) & $5(7.2)$ \\
(SAMA) & $3(4.3)$ \\
(LAMA) (LAMA + LABA) & $2(2.9)$ \\
(LAMA) (LAMA + LABA + ICS) & $1(1.4)$ \\
(LAMA) (SAMA) & $1(1.4)$ \\
(SAMA) (LAMA + LABA + ICS) & $1(1.4)$ \\
\hline
\end{tabular}




\section{References}

1. Global Asthma Network. Global Asthma Report 2018. Available online: http://globalasthmareport.org/ Global\%20Asthma\%20Report\%202018.pdf (accessed on 2 April 2019).

2. Brozek, J.; Bousquet, P.J.; Cagnani, C.E.B.; Bonini, S.; Canonica, G.W.; Casale, T.B.; Van Wijk, R.G.; Ohta, K.; Zuberbier, T.; Schünemann, H.J. Allergic Rhinitis and its Impact on Asthma (ARIA) guidelines: 2010 Revision. J. Allergy Clin. Immunol. 2010, 126, 466-476. [CrossRef]

3. De Groot, E.P.; Nijkamp, A.; Duiverman, E.J.; Brand, P.L.P. Allergic rhinitis is associated with poor asthma control in children with asthma. Thorax 2012, 67, 582-587. [CrossRef] [PubMed]

4. Price, D.; Zhang, Q.; Sazonov, V.; Yin, D.D.; Thomas, M. Effect of a concomitant diagnosis of allergic rhinitis on asthma-related health care use by adults. Clin. Exp. Allergy 2005, 35, 282-287. [CrossRef] [PubMed]

5. Scadding, G.C.W.; Berger, W.; Virchow, J.C.; Wickman, M.; Stock, P. Rhinitis and Asthma: Linking Diseases and Treatments. Allergy 2015, 2. Available online: https://keyopinions.info/downloads/rhinitis-asthmalinking-diseases-treatments/\# (accessed on 2 April 2019).

6. Van Der Leeuw, S.; Van Der Molen, T.; Dekhuijzen, P.R.; Fonseca, J.; A Van Gemert, F.; Van Wijk, R.G.; Kocks, J.W.; Oosterom, H.; A Riemersma, R.; Tsiligianni, I.G.; et al. The minimal clinically important difference of the control of allergic rhinitis and asthma test (CARAT): Cross-cultural validation and relation with pollen counts. NPJ. Prim. Care Respir. Med. 2015, 25, 14107. [CrossRef] [PubMed]

7. Deliu, M.; Belgrave, D.; Simpson, A.; Murray, C.S.; Kerry, G.; Custovic, A. Impact of rhinitis on asthma severity in school-age children. Allergy 2014, 69, 1515-1521. [CrossRef] [PubMed]

8. Oka, A.; Matsunaga, K.; Kamei, T.; Sakamoto, Y.; Hirano, T.; Hayata, A.; Akamatsu, K.; Kikuchi, T.; Hiramatsu, M.; Ichikawa, T.; et al. Ongoing Allergic Rhinitis Impairs Asthma Control by Enhancing the Lower Airway Inflammation. J. Allergy Clin. Immunol. Pract. 2014, 2, 172-178.e1. [CrossRef] [PubMed]

9. Feng, C.H.; Miller, M.D.; Simon, R.A. The united allergic airway: Connections between allergic rhinitis, asthma, and chronic sinusitis. Am. J. Rhinol. Allergy 2012, 26, 187-190. [CrossRef]

10. Giavina-Bianchi, P.; Aun, M.V.; Takejima, P.; Kalil,J.; Agondi, R.C. United airway disease: Current perspectives. J. Asthma Allergy 2016, 9, 93-100. [CrossRef]

11. Licari, A.; Castagnoli, R.; Denicolò, C.F.; Rossini, L.; Marseglia, A.; Marseglia, G.L. The Nose and the Lung: United Airway Disease? Front. Pediatr. 2017, 5, 44. [CrossRef]

12. Stachler, R.J. Comorbidities of asthma and the unified airway. Int. Forum Allergy Rhinol. 2015, 5, S17-S22. [CrossRef] [PubMed]

13. National Asthma Council Australia. Australian Asthma Handbook. Version 1.1. National Asthma Council Australia: Melbourne, VIC, Australia, 2015. Available online: http://www.asthmahandbook.org.au (accessed on 2 April 2019).

14. Azzi, E.A.; Kritikos, V.; Peters, M.J.; Price, D.B.; Srour, P.; Cvetkovski, B.; Bosnic-Anticevich, S. Understanding reliever overuse in patients purchasing over-the-counter short-acting beta2 agonists: An Australian community pharmacy-based survey. BMJ Open 2019, 9, e028995. [CrossRef] [PubMed]

15. Bosnic-Anticevich, S.; Kritikos, V.; Carter, V.; Yan, K.Y.; Armour, C.L.; Ryan, D.; Price, D. Lack of asthma and rhinitis control in general practitioner-managed patients prescribed fixed-dose combination therapy in Australia. J. Asthma 2017, 55, 684-694. [CrossRef] [PubMed]

16. Reddel, H.K.; Sawyer, S.M.; Everett, P.W.; Flood, P.V.; Peters, M. Asthma control in Australia: A cross-sectional web-based survey in a nationally representative population. Med. J. Aust. 2015, 202, 492-496. [CrossRef]

17. Tan, R.; Cvetkovski, B.; Kritikos, V.; Price, D.; Yan, K.; Smith, P.K.; Bosnic-Anticevitch, S. Identifying the hidden burden of allergic rhinitis (AR) in community pharmacy: A global phenomenon. Asthma Res. Pract. 2017, 3, 8. [CrossRef]

18. Boulet, L.-P.; Vervloet, D.; Magar, Y.; Foster, J.M. Adherence. Clin. Chest Med. 2012, 33, 405-417. [CrossRef]

19. A Slader, C.; Reddel, H.K.; Jenkins, C.R.; Armour, C.; Bosnic-Anticevich, S.Z. Complementary and alternative medicine use in asthma: Who is using what? Respirol 2006, 11, 373-387. [CrossRef]

20. Riley, I.L.; Jackson, B.; Crabtree, D.; Riebl, S.; Que, L.G.; Pleasants, R.; Boulware, L.E. A Scoping Review of International Barriers to Asthma Medication Adherence Mapped to the Theoretical Domains Framework. J. Allergy Clin. Immunol. Pract. 2020. [CrossRef]

21. Reddel, H.K.; Lembke, K.; Zwar, N.J. The cost of asthma medicines. Aust. Prescr. 2018, 41, 34-36. [CrossRef] 
22. Ponieman, D.; Wisnivesky, J.P.; Leventhal, H.; Musumeci-Szabó, T.J.; Halm, E.A. Impact of positive and negative beliefs about inhaled corticosteroids on adherence in inner-city asthmatic patients. Ann. Allergy, Asthma Immunol. 2009, 103, 38-42. [CrossRef]

23. Global Initiative for Asthma. Global Strategy for Asthma Management and Prevention-Updated 2020. Available online: https://ginasthma.org/wp-content/uploads/2020/04/GINA-2020-full-report_final-_wms. pdf (accessed on 24 April 2020).

24. Donnelly, J.E.; Donnelly, W.J.; Thong, Y.H. Inadequate parental understanding of asthma medications. Ann. Allergy 1989, 62, 337-341.

25. DiMatteo, M.R. Enhancing patient adherence to medical recommendations. JAMA 1994, 271, 79. [CrossRef] [PubMed]

26. Dekker, F.W.; E Dieleman, F.; A Kaptein, A.; Mulder, J.D. Compliance with pulmonary medication in general practice. Eur. Respir. J. 1993, 6, 886-890. [PubMed]

27. Australian Centre for Asthma Monitoring. Asthma in Australia 2011. AIHW: Canberra, Australia, 2011. Available online: https:/www.aihw.gov.au/reports/chronic-respiratory-conditions/asthma-in-australia-2011with-chapter-on-copd/contents/table-of-contents (accessed on 14 April 2019).

28. Armour, C.; Le May, K.; Saini, B.; Reddel, H.K.; Bosnic-Anticevich, S.Z.; Smith, L.; Burton, D.; Song, Y.J.C.; Alles, M.C.; Stewart, K.; et al. Using the Community Pharmacy to Identify Patients at Risk of Poor Asthma Control and Factors which Contribute to this Poor Control. J. Asthma 2011, 48, 914-922. [CrossRef]

29. Braido, F.; Chrystyn, H.; Baiardini, I.; Bosnic-Anticevich, S.; Van Der Molen, T.; Dandurand, R.J.; Chisholm, A.; Carter, V.; Price, D. "Trying, But Failing"-The Role of Inhaler Technique and Mode of Delivery in Respiratory Medication Adherence. J. Allergy Clin. Immunol. Pract. 2016, 4, 823-832. [CrossRef]

30. Jahedi, L.; Downie, S.R.; Saini, B.; Chan, H.-K.; Bosnic-Anticevich, S. Inhaler Technique in Asthma: How Does It Relate to Patients' Preferences and Attitudes Toward Their Inhalers? J. Aerosol Med. Pulm. Drug Deliv. 2017, 30, 42-52. [CrossRef]

31. Sinthia, Z.; Bosnic-Anticevich, B.C.; Elizabeth, A.; Azzi, P.S.; Rachel, T.; Vicky, K. Identifying Critical Errors: Addressing Inhaler Technique in the Context of Asthma Management. Pulm. Ther. 2018, 4, 1-12. [CrossRef]

32. Patel, M.R.; Kruger, D.J.; Cupal, S.; Zimmerman, M.A. Effect of Financial Stress and Positive Financial Behaviors on Cost-Related Nonadherence to Health Regimens Among Adults in a Community-Based Setting. Prev. Chronic Dis. 2016, 13. [CrossRef]

33. Cvetkovski, B.; Tan, R.; Kritikos, V.; Yan, K.; Azzi, E.A.; Srour, P.; Bosnic-Anticevich, S. A patient-centric analysis to identify key influences in allergic rhinitis management. NPJ Prim. Care Respir. Med. 2018, $28,34$. [CrossRef]

34. Compalati, E.; Ridolo, E.; Passalacqua, G.; Braido, F.; Villa, E.; Canonica, G.W. The link between allergic rhinitis and asthma: The united airways disease. Expert Rev. Clin. Immunol. 2010, 6, 413-423. [CrossRef]

35. Price, D.; Scadding, G.K.; Ryan, D.; Claus, B.; Canonica, G.W.; Mullol, J.; Klimek, L.; Pitman, R.; Acaster, S.; Murray, R.; et al. The hidden burden of adult allergic rhinitis: UK healthcare resource utilisation survey. Clin. Transl. Allergy 2015, 5, 39. [CrossRef] [PubMed]

36. Bosnic-Anticevitch, S.; Costa, E.; Menditto, E.; Lourenço, O.; Novellino, E.; Bialek, S.; Briedis, V.; Buonaiuto, R.; Chrystyn, H.; Cvetkovski, B.; et al. ARIA pharmacy 2018 "Allergic rhinitis care pathways for community pharmacy": AIRWAYS ICPs initiative (European Innovation Partnership on Active and Healthy Ageing, DG CONNECT and DG Sante) POLLAR (Impact of Air POLLution on Asthma and Rhinitis) GARD Demonstration project. Allergy 2019, 74, 1219-1236. [CrossRef]

37. Registry ANZCT. Trial Review_Pharmacy Trial Program (PTP)—Getting asthma under control using the skills of the community Pharmacist 2018. Available online: https:/www.anzctr.org.au/Trial/Registration/ TrialReview.aspx?id=374558\&isReview=true (accessed on 6 December 2019).

38. The University of Adelaide. Hugo Centre for Migration and Population Research-Pharmacy ARIA (PHARIA) 2019. Available online: https://www.adelaide.edu.au/hugo-centre/services/pharia (accessed on 8 March 2020).

39. Armour, C.; Bosnic-Anticevich, S.; Brillant, M.; Burton, D.; Emmerton, L.; Krass, I.; Saini, B.; Smith, L.; Stewart, K. Pharmacy Asthma Care Program (PACP) improves outcomes for patients in the community. Thorax 2007, 62, 496-592. [CrossRef] 
40. Saini, B.; Lemay, K.; Emmerton, L.; Krass, I.; Smith, L.; Bosnic-Anticevich, S.; Stewart, K.; Burton, D.; Armour, C. Asthma disease management-Australian pharmacists' interventions improve patients' asthma knowledge and this is sustained. Patient Educ. Couns. 2011, 83, 295-302. [CrossRef]

41. Juniper, E.; O'byrne, P.; Guyatt, G.; Ferrie, P.; King, D. Development and validation of a questionnaire to measure asthma control. Eur. Respir. J. 1999, 14, 902-907. [CrossRef] [PubMed]

42. Juniper, E.F.; Svensson, K.; Mörk, A.-C.; Ståhl, E. Measurement properties and interpretation of three shortened versions of the asthma control questionnaire. Respir. Med. 2005, 99, 553-558. [CrossRef] [PubMed]

43. National Center for Chronic Disease Prevention and Health Promotion. Calculating Proportion of Days Covered (PDC) for Antihypertensive and Antidiabetic Medications; an Evaluation Guide for Grantees. 2015. Available online: https://www.cdc.gov/dhdsp/docs/med-adherence-evaluation-tool.pdf (accessed on 3 June 2020).

44. American Pharmacist Association. Measuring Adherence 2020. Available online: https://www.pharmacist. com/measuring-adherence (accessed on 18 June 2020).

45. Raebel, M.A.; Schmittdiel, J.; Karter, A.J.; Konieczny, J.L.; Steiner, J.F. Standardizing Terminology and Definitions of Medication Adherence and Persistence in Research Employing Electronic Databases. Med. Care 2013, 51, S11-S21. [CrossRef]

46. Mart, M.F.; E Brummel, N.; Ely, E.W. The ABCDEF Bundle for the Respiratory Therapist. Respir. Care 2019, 64, 1561-1573. [CrossRef]

47. Juniper, E.F.; Bousquet, J.; Abetz, L.; Bateman, E.D. Identifying 'well-controlled' and 'not well-controlled' asthma using the Asthma Control Questionnaire. Respir. Med. 2006, 100, 616-621. [CrossRef]

48. Meltzer, E.O.; Busse, W.W.; Wenzel, S.E.; Belozeroff, V.; Weng, H.H.; Feng, J.; Chon, Y.; Chiou, C.-F.; Globe, D.; Lin, S.-L. Use of the Asthma Control Questionnaire to predict future risk of asthma exacerbation. J. Allergy Clin. Immunol. 2011, 127, 167-172. [CrossRef]

49. Australian Institute of Health and Welfare. Respiratory Medication Use in Australia 2003-2013-Treatment of Asthma and COPD. 2015. Available online: https://www.cdc.gov/dhdsp/docs/med-adherence-evaluationtool.pdf (accessed on 3 June 2020).

50. Amin, S.; Soliman, M.; McIvor, A.; Cave, A.; Cabrera, C. Usage Patterns of Short-Acting $\beta 2$-Agonists and Inhaled Corticosteroids in Asthma: A Targeted Literature Review. J. Allergy Clin. Immunol. Pr. 2020, 8, 2556-2564. [CrossRef]

51. DiSantostefano, R.L.; Yeakey, A.M.; Raphiou, I.; Stempel, D.A. An evaluation of asthma medication utilization for risk evaluation and mitigation strategies (REMS) in the United States: 2005-2011. J. Asthma 2013, 50, 776-782. [CrossRef] [PubMed]

52. Price, D.; Fletcher, M.; Van Der Molen, T. Asthma control and management in 8,000 European patients: The REcognise Asthma and LInk to Symptoms and Experience (REALISE) survey. NPJ Prim. Care Respir. Med. 2014, 24, 14009. [CrossRef] [PubMed]

53. Hull, S.A.; McKibben, S.; Homer, K.; Taylor, S.J.; Pike, K.C.; Griffiths, C. Asthma prescribing, ethnicity and risk of hospital admission: An analysis of 35,864 linked primary and secondary care records in East London. NPJ. Prim. Care Respir. Med. 2016, 26, 16049. [CrossRef]

54. Houghton, L.A.; Lee, A.S.; Badri, H.; DeVault, K.R.; Smith, J.A. Respiratory disease and the oesophagus: Reflux, reflexes and microaspiration. Nat. Rev. Gastroenterol. Hepatol. 2016, 13, 445-460. [CrossRef]

55. Razak, M.R.A.; Chirakalwasan, N. Obstructive sleep apnea and asthma. Asian Pac. J. Allergy Immunol. 2016, 34, 265-271.

56. Mohanan, S.; Tapp, H.; McWilliams, A.; Dulin, M. Obesity and asthma: Pathophysiology and implications for diagnosis and management in primary care. Exp. Boil. Med. 2014, 239, 1531-1540. [CrossRef]

57. Alvarez, G.G.; Fitzgerald, J. A Systematic Review of the Psychological Risk Factors Associated with Near Fatal Asthma or Fatal Asthma. Respiration 2006, 74, 228-236. [CrossRef]

58. Scott, K.M.; Von Korff, M.; Ormel, J.; Zhang, M.-Y.; Bruffaerts, R.; Alonso, J.; Kessler, R.C.; Tachimori, H.; Karam, E.; Levinson, D.; et al. Mental disorders among adults with asthma: Results from the World Mental Health Survey. Gen. Hosp. Psychiatry 2007, 29, 123-133. [CrossRef]

59. Australian Institute of Health and Welfare. Using PBS and MBS Data to Report on the Treatment and Management of Chronic Respiratory Conditions 2016-17 2018. Available online: https://www.aihw. gov.au/getmedia/ae99bd43-684d-44dd-b7b1-3ef8f700d817/aihw-acm-37.pdf.aspx?inline=true (accessed on 1 April 2020). 
60. Tinkelman, D.; Price, D.; Nordyke, R.J.; Halbert, R.J. Misdiagnosis of COPD and Asthma in Primary Care Patients 40 Years of Age and Over. J. Asthma 2006, 43, 75-80. [CrossRef]

61. Kostikas, K.; Clemens, A.; Patalano, F. The asthma-COPD overlap syndrome: Do we really need another syndrome in the already complex matrix of airway disease? Int. J. Chronic Obstr. Pulm. Dis. 2016, 11,1297-1306. [CrossRef]

62. Walters, J.A.; Hansen, E.; Walters, E.H.; Wood-Baker, R. Under-diagnosis of chronic obstructive pulmonary disease: A qualitative study in primary care. Respir. Med. 2008, 102, 738-743. [CrossRef] [PubMed]

63. Bae, Y.-J.; Kim, T.-B.; Jee, Y.-K.; Park, H.-W.; Chang, Y.-S.; Cho, S.-H.; Cho, Y.S.; Moon, H.-B. Severe Asthma Patients in Korea Overestimate Their Adherence to Inhaled Corticosteroids. J. Asthma 2009, 46, 591-595. [CrossRef] [PubMed]

64. Bender, B.G.; Pedan, A.; Varasteh, L. Adherence and persistence with fluticasone propionate/salmeterol combination therapy. J. Allergy Clin. Immunol. 2006, 118, 899-904. [CrossRef]

65. Broder, M.S.; Chang, E.Y.; Kamath, T.; Sapra, S. Poor disease control among insured users of high-dose combination therapy for asthma. Allergy Asthma Proc. 2010, 31, 60-67. [CrossRef]

66. Hinyard, L.; Geremakis, C.; Temprano, J. Differences in Asthma Controller Medication Adherence by Age and Gender. J. Allergy Clin. Immunol. 2012, 129, AB66. [CrossRef]

67. Mäkelä, M.J.; Backer, V.; Hedegaard, M.; Larsson, K. Adherence to inhaled therapies, health outcomes and costs in patients with asthma and COPD. Respir. Med. 2013, 107, 1481-1490. [CrossRef]

68. Australian Government Department of Health.Pharmaceutical Benefits: Fees, Patient Contributions and Safety Net Thresholds 2020. Available online: https:/www.pbs.gov.au/info/healthpro/explanatory-notes/ front/fee (accessed on 12 September 2020).

69. Australian Government Department of social services. Concession and Health Cards 2014. Available online: https://www.dss.gov.au/about-the-department/benefits-payments/concession-and-health-cards\#: $\sim\{\}:$ text=The $\% 20$ Australian\%20Government $\mid \mathrm{T} 1 \backslash$ textquoterights $\% 20$ main $\% 20$ purpose, services $\% 2 \mathrm{C} \% 20$ at $\%$ 20a\%20cheaper\%20rate (accessed on 12 September 2020).

70. Small, M.; Anderson, P.; Vickers, A.; Kay, S.; Fermer, S. Importance of inhaler-device satisfaction in asthma treatment: Real-world observations of physician-observed compliance and clinical/patient-reported outcomes. Adv. Ther. 2011, 28, 202-212. [CrossRef]

71. Chapman, K.; Friberg, K.; Balter, M.; Hyland, R.; Alexander, M.; Abboud, R.; Peters, S.; Jennings, B. Albuterol via Turbuhaler Versus Albuterol via Pressurized Metered-Dose Inhaler in Asthma. Ann. Allergy Asthma Immunol. 1997, 78, 59-63. [CrossRef]

72. Darba, J.; Ramírez, G.; Francoli-Martínez, P.; Sicras-Mainar, A.; Torvinen, S.; La Rosa, R.S.-D. The importance of inhaler devices: The choice of inhaler device may lead to suboptimal adherence in COPD patients. Int. J. Chronic Obstr. Pulm. Dis. 2015, 10, 2335-2345. [CrossRef]

73. Roy, A.; Battle, K.; Lurslurchachai, L.; A Halm, E.; Wisnivesky, J.P. Inhaler device, administration technique, and adherence to inhaled corticosteroids in patients with asthma. Prim. Care Respir. J. 2011, 20, 148-154. [CrossRef] [PubMed]

(C) 2020 by the authors. Licensee MDPI, Basel, Switzerland. This article is an open access article distributed under the terms and conditions of the Creative Commons Attribution (CC BY) license (http://creativecommons.org/licenses/by/4.0/). 